\title{
The Quest for the Perfect Prostate Biopsy Continues
}

Leonard G. Gomella

Department of Urology, Thomas Jefferson University, Kimmel Cancer Center, Leonard.Gomella@jefferson.edu

Follow this and additional works at: https://jdc.jefferson.edu/kimmelccfp

Part of the Urology Commons

Let us know how access to this document benefits you

\section{Recommended Citation}

Gomella, Leonard G., "The Quest for the Perfect Prostate Biopsy Continues" (2012). Kimmel

Cancer Center Faculty Papers. Paper 25.

https://jdc.jefferson.edu/kimmelccfp/25

This Article is brought to you for free and open access by the Jefferson Digital Commons. The Jefferson Digital Commons is a service of Thomas Jefferson University's Center for Teaching and Learning (CTL). The Commons is a showcase for Jefferson books and journals, peer-reviewed scholarly publications, unique historical collections from the University archives, and teaching tools. The Jefferson Digital Commons allows researchers and interested readers anywhere in the world to learn about and keep up to date with Jefferson scholarship. This article has been accepted for inclusion in Kimmel Cancer Center Faculty Papers by an authorized administrator of the Jefferson Digital Commons. For more information, please contact: JeffersonDigitalCommons@jefferson.edu. 
Guest Editorial

Journal of Urology June, 2012

"The Quest for the Perfect Prostate Biopsy Continues"

Leonard G. Gomella, MD, FACS

Chairman, Department of Urology

Thomas Jefferson University

Kimmel Cancer Center

1025 Walnut Street, 1102

Philadelphia, PA 19107

215-955-1702/215-923-1884 (fax)

Until well into the 1980's, biopsy of the prostate often relied on a few cores using a device such as the Vim-Silverman needle digitally guided either trans-

perineally or transrectally into a palpably abnormal prostate. In this pre-PSA era, prostate cancers were often detected at an advanced clinical stage. The modern era of prostate biopsy was ushered in the late 1980's with the development of the spring loaded biopsy needle and the trans-rectal ultrasound (TRUS) probe. Since that time, the state of the art has evolved from the TRUS directed biopsy of suspicious lesions, to the sextant and now extended 10-12 core biopsy schema using local anesthesia. The decision to perform prostate biopsy today is often based on the interpretation of changes in serum PSA, leading to cancer detection in palpably normal prostate glands.

Our current "gold standard" prostate biopsy is based on standard gray scale TRUS imaging. Although early investigations suggested that prostate cancer is seen as a "hypoechoic lesion" on TRUS, the reality today is that most PSA detected cancers have a highly variable appearance. These cancers do not demonstrate any unique characteristics on gray scale imaging. While a sonographically distinct lesion is biopsied when seen, distinguishing benign from malignant tissue with standard ultrasound is challenging. (1) Standard gray scale TRUS is very effective at providing an accurate size determination as well as guiding the biopsy needle ensuring an adequate sampling of the various regions of the gland. It usually falls short in the detection of all prostate cancers that may be present due to the common small and multifocal nature of the disease.

Changes in the management of prostate cancer require a much more careful assessment of the prostate cancer than ever. No longer is it appropriate to identify simply the largest or index tumor and make a simple diagnosis of prostate cancer. Standard and evolving approaches, such as active surveillance and focal therapy, ideally require that all lesions within the prostate be detected and characterized to determine the appropriate course of action. 
Multifocality is the rule rather than the exception and identifying the tumor with the aggressive phenotype can no longer be made based on size alone. Using a saturation biopsy approach with 20 or more cores, may not be appropriate for the initial biopsy but has utility in the repeat biopsy setting. (2)

Many imaging technologies have been studied to improve the biopsy yield. Color Doppler ultrasound enhanced prostate biopsy has limitations but when combined with microbubble contrast agents, improvements are seen. Work at our Jefferson Prostate Diagnostic center and by others has demonstrated that hypervascular prostate cancers can be detected with fewer biopsy cores using microbubble contrast-enhanced ultrasound (CEUS). Most significantly, cancers with higher Gleason grades cancers are more likely to be detected with CEUS when compared to other TRUS approaches. $(1,3)$ Even with this improvement in the detection of higher grade cancers, systematic biopsies are still required with these techniques to optimize the detection of prostate cancer. Several papers in this issue of the Journal of Urology address prostate biopsy and tumor detection.

Elastography, also known as elastosonography, represents a newer TRUS based technique that relies on alterations in tissue stiffness that may indicate the presence of prostate cancer. In our Jefferson Prostate Diagnostic Center's initial elastography experience, areas identified in the prostate with an abnormal elastography pattern were twice as likely to be prostate cancer when compared to biopsies in areas of normal elasticity. (4) Using real time elastography, Brock and associates also noted a higher biopsy yield, but in similar fashion to the CEUS experience previously cited, it was not sensitive enough to omit the systematic biopsies. (5)

MRI has enjoyed a significant growth in the management of prostate cancer with improvements in the multi parametric MRI such as higher power scanners and newer imaging protocols. Although very cumbersome, MRI directed biopsies are performed at selected centers. In spite of the enthusiasm for more complete detection of all prostate lesions by MRI, Rosenkrantz and associates note that many tumors are not detected by these MRI techniques and suggest the further study of the missed tumors be used to improve MRI imaging (6). Fusion of MRI with TRUS imaging and biopsy is a promising approach to gain the benefits of both technologies. (7)

A potential advantage of MRl is in the identification of anteriorly located tumors that may escape a transrectal needle biopsy approach. Huo and associates report on their experience with initial transperineal template biopsy. (8) The transperineal approach potentially allows a more complete biopsy of the prostate including the anterior zone. They note only a fair pathologic 
agreement with the final radical prostatectomy specimens and suggest larger prostates require more biopsies using this approach.

While the short term risks of prostate biopsy are well known, little data is available on the long term implications of repeat transrectal biopsy on cancer outcomes. It is reassuring that in the era of active surveillance with mandated repeat prostate biopsies, in a cohort analysis of over 2700 men in the SEARCH database a repeat prostate biopsy did not demonstrate an increased risk of biochemical recurrence following radical prostatectomy. (9)

Our current biopsy methods adequately identify larger non-palpable lesions. As we move to earlier detection of prostate cancer, the lesions become smaller and more difficult to detect by our standard biopsy and imaging techniques. Some argue that these smaller lesions are clinically insignificant and of no clinical consequence. This adds fuel to the ongoing prostate cancer screening controversy by causing detection and overtreatment of small cancers that will never harm the patient. (10) However, these smaller lesions may exhibit characteristics of clinically aggressive disease regardless of size and may impact treatment decisions particularly in men with long life expectancies. In our quest for the perfect prostate biopsy, identifying lesions by needle biopsy or imaging may not be enough. Methods to more precisely discriminate aggressive prostate cancer from indolent disease should also be a part of our biopsy efforts going forward.

1. Trabulsi EJ, Sackett D, Gomella LG, Halpern EJ. Enhanced transrectal ultrasound modalities in the diagnosis of prostate cancer. Urology. 2010 Nov;76(5): 1025-33.

2. Zaytoun OM, Moussa AS, Gao T, et al. Office based transrectal saturation biopsy improves prostate cancer detection compared to extended biopsy in the repeat biopsy population. J Urol. 2011 Sep; 186(3):850-4.

3. Mitterberger M, Pinggera GM, Horninger W, et al. Comparison of contrast enhanced color Doppler targeted biopsy to conventional systematic biopsy: impact on Gleason score. J Urol. 2007 Aug; 178(2):464-8

4. Nelson ED, Slotoroff CB, Gomella LG, Halpern EJ. Targeted biopsy of the prostate: the impact of color Doppler imaging and elastography on prostate cancer detection and Gleason score. Urology. 2007 Dec;70(6): 1 136-40

5. Brock M, von Bodman C, Palisaar RJ, et al. The impact of real-time elastography guiding a systematic prostate biopsy to improve cancer detection rate: A prospective study with 353 patients. J Urol June 2012 
6. Rosenkrantz AB, Mendrinos S, Babb JS, Taneja SS. Prostate Cancer Foci Detected on Multi-Parametric MRI are Histologically Distinct from Those Not Detected. J Urol, XXX June 2012

7. Pinto PA, Chung PH, Rastinehad AR, et al. Magnetic resonance imaging/ultrasound fusion guided prostate biopsy improves cancer detection following transrectal ultrasound biopsy and correlates with multiparametric magnetic resonance imaging. J Urol. 2011 Oct; 186(4): 1281-5

8. Huo ASY, Hossack T, Symons JLP, et al. Accuracy of Primary Systematic Template-guided Transperineal Biopsy of the Prostate in Locating Prostate Cancer - A Comparison with Radical Prostatectomy Specimens. J Urol , XXX June 2012

9. Kopp RP, Stroup SP, Schroeck F, et al. Are Repeat Prostate Biopsies Safe? A Cohort Analysis from the SEARCH Database. J Urol, XXX June 2012

10. Gomella LG, Liu XS, Trabulsi EJ, et al. Screening for prostate cancer: the current evidence of guidelines controversy. Can J Urol 201 1; 18(5):5875-5883 